\title{
Peletização de Sementes Florestais no Brasil: Uma Atualização
}

\author{
Sérgio Roberto Garcia dos Santos ${ }^{1}$ \\ ${ }^{1}$ Seção de Silvicultura, Instituto Florestal, São Paulo/SP, Brasil
}

\begin{abstract}
RESUMO
No Brasil, os estudos com peletização de sementes de espécies florestais ainda são escassos; as razões prováveis são o alto custo desta técnica e o pouco uso da semeadura direta com espécies florestais. Considerando que as sementes florestais apresentam grande variação de tamanho, forma e peso para as diferentes espécies, o uso da peletização apresenta-se como uma alternativa promissora como forma de uniformizar tamanhos e formatos, favorecendo o seu uso em projetos de restauração ecológica através da melhoria da plantabilidade e/ou com espécies para as quais foi desenvolvido um trabalho de melhoramento. A semente peletizada apresenta ainda outras vantagens, pois permite a incorporação de vários produtos que ajudam no bom desenvolvimento da muda, diminuindo os custos de produção. Deste modo, há um ganho relativo à segurança no trabalho, pois proporciona uma redução de poeira e inalação (ex. agrotóxicos) pelos operadores e também quanto a proteção ao meio ambiente.
\end{abstract}

Palavras-chave: incorporação de produtos, plantabilidade, recobrimento.

\section{Pelleting Forest Seeds in Brazil: An Update}

\begin{abstract}
In Brazil, the studies with pelleting of seed of forest species are still scarce; the likely reasons are the high cost of this technique and the little use of direct seeding with forest species. Whereas forestry seeds show great variation in size, shape and weight to the different species, the use of the pelleting is presented as a promising alternative as way to standardize sizes and shapes, favoring its use in ecological restoration projects by improving of plantability and / or species for which it was developed a breeding work. The pelleted seeds has other advantages, as it allow the incorporation of several products that helping in proper development of molting, reducing production costs. Thus, there is a gain on the safety at work, it provides a reduction of dust and of inhalation (e.g. pesticides) by operators as well as the protection of the environment.
\end{abstract}

Keywords: incorporation of products, plantability, coating. 


\section{INTRODUÇÃO}

O processo de recobrimento de sementes a partir da década de 90, evolui de forma que hoje se encontra no topo da indústria sementeira, em função das preocupações relativas à segurança no trabalho e proteção ao meio ambiente, bem como a semeadura de precisão. Esta tecnologia tem como vantagem a incorporação de novos produtos (adubos, hormônios e herbicidas entre outros) à semente, melhorando a sua plantabilidade, o seu estabelecimento no solo e propiciando a redução dos custos de produção (Baudet \& Peres, 2004).

Com o uso desta técnica há proteção das sementes contra o ataque de aves, insetos e patógenos, fatores edafoclimáticos adversos, alta incidência solar e maior resistência ao deslocamento das sementes pela ação erosiva (Falck, 2005; Oliveira et al., 2010), todas estas vantagens dependem do tipo de ingrediente ativo acrescentado no recobrimento das sementes.

O termo semente peletizada ou péletes não faz parte do dicionário oficial da língua portuguesa, mas é popularmente conhecido como sementes pelotizadas, bolotizadas ou piluladas, que seriam os corretos, mas não são utilizados; esta denominação é adaptada do inglês (Silva \& Nascimento, 2009).

A ideia de recobrir sementes não é nova. A primeira patente relacionada com o recobrimento de sementes foi emitida em 1868. Entretanto, sua aplicação comercial não obteve um interesse real até 1940, ano em que Volgelsang aparece como um dos primeiros defensores da "peletização de sementes". Entusiasmado com os benefícios potenciais deste processo e com o objetivo de produzir e comercializar sementes peletizadas, Vogelsang criou a primeira companhia comercial em 1946, formalizando a patente deste processo com sementes de beterraba pela CERES (Roos \& Moore, 1975; Giménez-Sampaio \& Sampaio, 2009). Inicialmente os materiais e procedimentos para revestimento foram originalmente desenvolvidos para a indústria farmacêutica (Taylor et al., 2001).

O êxito conseguido na semeadura da beterraba, utilizando sementes peletizadas, foi rapidamente adaptado para outras espécies com dificuldades durante o estabelecimento de plântulas, como fumo, alface, tomate e outras. Atualmente, esta técnica tem sido utilizada principalmente em sementes de várias hortaliças, flores e praticamente qualquer espécie pode ter suas sementes peletizadas (Silva \& Nascimento, 2009).

Além da peletização, a tecnologia de recobrimento das sementes pode produzir também a peliculização e a incrustação (Giménez-Sampaio \& Sampaio, 1994; Gadotti \& Puchala, 2010), sendo os três tipos de revestimentos caracterizados resumidamente a seguir. $\mathrm{Na}$ peliculização as sementes são revestidas com um filme líquido, geralmente feito em camada única, sem alterar o seu peso e formato, garantindo ótima adesão e distribuição dos ingredientes ativos. Na peletização a semente possui seu tamanho e formato modificado em relação ao original, ganhando uma conformação mais arredondada. A incrustação é um estágio intermediário entre as duas tecnologias anteriores e consiste de um processo de recobrimento que aumenta o peso da semente melhorando a sua aparência. Sendo que a peletização e a incrustação conferem maior flexibilidade ao tratamento de sementes.

\subsection{Caracterização e produção de péletes}

A peletização é uma técnica que consiste no revestimento das sementes com um material seco, inerte, de granulometria fina (enchimento); um material cimentante (adesivo) que deve ser solúvel em água e materiais de cobertura e acabamento. Este tratamento permite dar à semente uma forma arredondada, aumentando o seu tamanho e facilitando assim a sua distribuição, seja ela manual ou mecânica (Nascimento et al., 2009; Lopes \& Nascimento, 2012).

O processo de peletização das sementes permite a aplicação de pequenas quantidades de nutrientes, reguladores de crescimento e inoculantes, além de inseticidas, fungicidas e repelentes de pássaros. Entretanto, alguns tipos de péletes constituem barreiras para a germinação das sementes, retardando o crescimento e causando a desuniformidade na emergência das plântulas (Silva \& Nakagawa, 1998a).

Em razão deste problema, barreira à germinação, que é o principal entrave para a popularização desta técnica (Oliveira, 2008), o tratamento de pré-condicionamento (osmótico ou hídrico) ou priming tem sido utilizado em sementes de várias culturas entre elas as florestais [um exemplo é com Guazuma ulmifolia (Nascimento, 2011)], com o objetivo de aumentar e uniformizar a velocidade de germinação e de emergência de plântulas, consequentemente aumentando a resistência das 
mesmas aos estresses edafoclimáticos. Outros benefícios do condicionamento osmótico têm sido relatados: melhor desempenho das sementes condicionadas em temperaturas sub ou super ótimas; maior emergência das plântulas em solos com alta concentração salina e minimização do efeito de fungos que causam damping-off (Baudet \& Peske, 2007).

Segundo Baudet \& Peres (2004) os detalhes específicos desta metodologia não são informados, pois são considerados segredos comerciais, e deste modo, são disponíveis somente a descrição geral de processos e insumos utilizados.

Os materiais utilizados como cobertura ou enchimento dos péletes são os mais variados. A escolha destes dependerá do tipo de semente a ser recoberta, dos objetivos do recobrimento, das condições ambientais a que serão expostas no plantio e, das possíveis compatibilidades com outros materiais e tratamentos administrados de modo combinado às sementes. Esses materiais (de cobertura ou enchimento) podem ser de origem mineral ou orgânica, como por exemplo: argila, trípoli, terra de diatomáceas, serragem, casca, farinha de osso, farinha de sangue, calcário e outros (Oliveira et al., 2006).

Os polímeros que compõem os adesivos são divididos em orgânicos, minerais e sintéticos (Medeiros et al., 2004). Os mais utilizados são os orgânicos: amidos, resinas naturais, açucares, colas de origem animal e mucilagens vegetais (Baudet \& Peres, 2004). Dentre os adesivos minerais e sintéticos existentes podem ser citados: azeites minerais, polivinil pirrolidona, álcool polivinílico, poliuretanos e resinas plásticas (Giménez-Sampaio \& Sampaio, 2009).

Os adesivos devem ter como características, serem biodegradáveis e permitirem uma germinação rápida, favorecendo as trocas gasosas e a absorção de água, não dificultando a protrusão radicular e a emergência da parte aérea. A fórmula utilizada deve permitir uma distribuição homogênea e ao mesmo tempo firme e durável sobre o tegumento, além de proporcionar uma secagem rápida e uma boa aparência à semente (Baudet \& Peres, 2004). A capacidade de recobrimento da semente, segundo os mesmos autores, é dependente das características do tegumento como textura, rugosidade e pilosidade.

Com o avanço no desenvolvimento de novos polímeros, esta tecnologia tem possibilitado o aumento da penetração e da fixação de produtos ativos, melhorando, consequentemente, a distribuição das substancias ativas nas sementes, além de reduzir as quantidades utilizadas dos produtos químicos e a consequente poluição ambiental (Karam et al., 2007).

Os equipamentos utilizados para o recobrimento ou peletização, envolvem sistemas com agitação das partículas, por exemplo, tambores, misturadores, leitos móveis e centrifugas. Entre esses equipamentos, os tambores rotativos e os leitos móveis são os mais utilizados na produção de partículas recobertas. Nos tambores rotativos (peletização convencional), as partículas a serem recobertas são agrupadas em movimento e a suspensão de recobrimento é pulverizada sobre as mesmas. Frequentemente, um gás aquecido é fornecido ao sistema para a secagem das partículas (Costa, 2003).

Simplificadamente, um lote de sementes peletizadas pode ser obtido por meio da sua agitação no interior de um tambor rotativo, onde se adiciona, alternadamente, um aglutinante (adesivo) e o material inerte. $\mathrm{O}$ adesivo pode incorporar-se mediante pulverização, nebulização ou atomização, enquanto o material inerte costuma-se incorporar mediante pulverização. A ação de rodar e resvalar de umas sementes sobre as outras faz o pó grudar na superfície da semente e finalmente, se forma o pélete, cujo formato é normalmente esférico (IPEF, 2004).

\subsection{Vantagens e desvantagens desta técnica}

As principais vantagens do recobrimento (peletização) das sementes são: 1- melhoria da plantabilidade (mecânica ou manual); 2- maior eficiência dos produtos fitossanitários aderidos aos péletes; 3 - maior segurança na incorporação dos produtos fitossanitários por funcionários e no manuseio pelo agricultor; 4- redução de poeira e inalação dos agrotóxicos pelos operadores; 5- redução da quantidade de produtos químicos utilizados (no pélete) e a consequente diminuição da poluição ambiental; 6- possibilidade de inclusão de agrotóxicos, produtos biológicos e macro e micro nutrientes em um único pélete; 7- melhor retenção do tratamento sobre a semente; 8 - proteção para a semente contra danos mecânicos no manuseio; 9 - ajuda a proteger as sementes armazenadas sob condições de alta umidade; 10- melhora a aparência das sementes, com cores atrativas, informando sobre a alta qualidade, 
produtor ou o tratamento aplicado e 11- permite a rastreabilidade visual do produto (Baudet \& Peres, 2004; Reichenbach, 2004; Karam et al., 2007; Lopes \& Nascimento, 2012).

Em contraposição, esses mesmos autores, elencam algumas das desvantagens desta técnica. São elas: 1- maior custo do processo de recobrimento; 2 - necessidade de produtos específicos (aglomerantes, adesivos, corantes e polímeros); 3- requer maquinário com alta precisão na dosagem dos produtos e 4- o pélete pode atuar como uma barreira física e dificultar a emissão da raiz primária com atraso na germinação das sementes.

\subsection{Peletização em espécies florestais: nativas e exóticas}

No Brasil, os estudos com peletização de sementes de espécies florestais ainda são inexpressivos e a sua ausência está provavelmente ligada ao alto custo deste processo e a falta de tradição em semeadura direta com espécies florestais (Almeida, 2004). Deste modo, há poucas informações sobre o comportamento dessas sementes quando recobertas e armazenadas, mas as pesquisas que vem sendo desenvolvidas estão ampliando o número de espécies florestais com metodologia conhecida (Almeida, 2004; Oliveira et al., 2010; Nascimento, 2011; Pozitano, 2011).

Em uma experiência pioneira no Brasil, envolvendo a peletização de sementes florestais, foi realizada em 1989 a semeadura direta, via aérea, em áreas da Serra do Mar, degradadas pela poluição atmosférica em Cubatão (SP). Das 33 espécies utilizadas, duas (Tibouchina pulchra e T. mutabilis) conhecidas como manacás-da-serra tiveram suas sementes peletizadas para contornar as limitações advindas do reduzido peso das mesmas e pela retenção após a queda na vegetação herbácea e arbustiva existente no local, para tanto foi desenvolvida uma técnica de peletização de sementes em gel hidrofílico que, através do aumento do peso e volume, permitiu seu lançamento por via aérea e, como resultados, obteve um incremento significativo na regeneração do manacá-da-serra, quando comparada à regeneração natural (Pompéia et al., 1992).

Além do baixo peso das sementes, este processo também é indicado aquelas que apresentam tamanho diminuto (Lopes \& Nascimento, 2012), como ocorre com outras espécies de arbóreas nativas (exemplos: Ficus guaranitica, F. insipida e Maclura tinctoria).
O recobrimento das sementes de espécies florestais pode ser utilizado em projetos de restauração ecológica, através da semeadura direta, e a diversidade de espécies é imperativa neste tipo de projeto (Oliveira et al., 2010).

A peletização das sementes florestais também se mostra interessante e eficiente segundo Almeida (2004) quando as condições topográficas de uma área, para implantação de florestas, permitirem a mecanização. A semeadura mecanizada, em razão da necessidade de se utilizar uma diversidade de espécies, fica inviabilizada, pois, deparara-se com sementes de tamanho e formato distintos. Neste sentido o uso de sementes peletizadas apresenta-se como uma técnica que permite uniformizar o tamanho e o formato destas favorecendo a mecanização da semeadura.

Para espécies florestais nativas já há várias pesquisas realizadas que envolvem a peletização ou o recobrimento de sementes. Podendo serem citadas as respectivas espécies e estudos: 1- Leandra cardiophylla, Tibouchina holosericea e T. pulchra (Pradella et al., 1989); 2- Cedrela fissilis, Copaifera langsdorffi, Enterolobium contortisiliquum, Guazuma ulmifolia, Lithraea molleoides, Piptadenia gonoacantha, Senna macranthera, S. multijuga, Sesbania virgata, Solonum granuloso-leprosum, Tabebuia serratifolia e Trema micrantha (Almeida, 2004); 3- Schizolobium amazonicum, Enterolobium contortisiliquum e E. schomburgkii (Oliveira et al., 2010); 4- Senna macranthera (Pozitano, 2011); 5- Guazuma ulmifolia (Nascimento, 2011); 6- Bowdichia virgilioides (Montanhim, 2013) e 7- Mabea fistulifera (Rosso, 2013). Com relação ao uso de peletização ou recobrimento em sementes florestais de espécies exóticas são conhecidos os trabalhos com Eucalyptus urophylla e Eucalyptus grandis (Kanashiro et al, 1978; Silveira, 1998), Pinus elliottii (Dias, 1973; Falck, 2005) e Leucaena leucocephala (Sá, 1997).

Em plantios florestais comerciais, com espécies exóticas, esta técnica já é bastante difundida com Eucalyptus spp., pois as suas sementes além de diminutas, apresentam uma alta qualidade genética e um elevado valor (Kanashiro et al., 1978). Na produção de mudas, conforme observam Walker et al. (2011) este processo é interessante para espécies com sementes muito pequenas como as de eucalipto (exemplos: Eucalyptus grandis e E. saligna), pois não há necessidade de realizar desbaste de plântulas, uma vez que é possível semear uma semente por tubete. O Instituto de Pesquisas e 
Estudos Florestais (IPEF), localizado em Piracicaba (SP), foi a primeira instituição a distribuir comercialmente sementes peletizadas de essências florestais, pois a tecnologia já era desenvolvida desde 2003. As espécies e híbridos comercializados desde então são: Eucalyptus grandis, E. camaldulensis, E. urophylla e E. urophylla x E. grandis (IPEF, 2004). Com relação as sementes do gênero Pinus spp. entretanto ainda pouco se sabe sobre o uso desta técnica (Falck, 2005).

\subsection{Preparo artesanal dos péletes de sementes florestais (confecção)}

Em razão da dificuldade em se obter informações sobre a produção de péletes, foram então desenvolvidos processos alternativos para a produção de sementes peletizadas, visando atender pequenas quantidades, consumo próprio ou propiciar uma redução de custos.

Um destes processos foi utilizado por Almeida (2004) para produzir péletes de sementes florestais. A autora fez uso de uma betoneira de $120 \mathrm{~L}$ (marca Menegotti), usada na construção civil, sem palhetas internas, e em rotação constante de $32 \mathrm{rpm}$. O adesivo utilizado foi introduzido por meio de uma pistola de funilaria, ligada a um compressor com saída e regulagem de pressão de $15-25 \mathrm{kgf} / \mathrm{cm}^{2}$. A aplicação do material de enchimento foi realizada manualmente, mediante a uso de uma peneira pequena de malha aproximada de $0,65 \mathrm{~mm}$.

A peletização, segundo a mesma autora, foi realizada colocando-se as sementes na betoneira e, alternadamente colocando o adesivo e o material de enchimento até os péletes adquirirem o tamanho e o formato desejados. Frequentemente os péletes foram sendo peneirados utilizando uma peneira de malha circular de $2,26 \mathrm{~mm}$ de diâmetro; os péletes que ficavam retidos na peneira eram separados e os restantes retornavam à betoneira para dar continuidade ao processo. Após todos os péletes adquirirem tamanho e formato desejado, os mesmos eram colocados para secar à sombra por 48 horas.

Outro processo, este desenvolvido pela Empresa Brasileira de Pesquisa Agropecuária- EMBRAPA (Lopes \& Nascimento, 2012), é indicado para a produção de sementes peletizadas de eucalipto. Neste processo são utilizados basicamente dois equipamentos, a betoneira e o aplicador de cimentante.

Para tanto seguem as indicações fornecidas por Lopes \& Nascimento (2012) dos equipamentos e procedimentos adotados para a obtenção das sementes peletizadas:

- Betoneira - A Embrapa Hortaliças desenvolveu uma betoneira pequena, pois não são encontrados fornecedores nacionais ou estrangeiros de equipamentos para confecção de péletes (especialmente para laboratório), com bojo de fundo arredondado, de material plástico, acionada por manivela, colocada ao lado do bojo, sendo os dois eixos interligados por corrente e polia dentada. O conjunto foi montado em um cavalete de metal dotado de ajustes para altura e para inclinação dos eixos (da betoneira e da manivela). Posteriormente, adaptou-se uma betoneira motorizada, a partir de um equipamento para misturar concreto, com capacidade de $150 \mathrm{~L}$, com rotação de $30 \mathrm{rpm}$.

- Aplicador de cimentante - A suspensão contendo cimentante é aplicada por aspersão, utilizando uma pistola de pintura de ar comprimido de baixa pressão, que funcione a $1,5 \mathrm{kgf} / \mathrm{cm}^{2}\left(10 \mathrm{lb} / \mathrm{pol}^{2}\right)$. O uso de pressão elevada provoca a remoção tanto do material em pó quanto das sementes para fora da betoneira. As pistolas possuem geralmente dispositivos para regular a vazão e o tamanho das gotas. A pressão é fornecida por um compressor de ar, dotado de uma válvula reguladora de pressão. Esta válvula deve ficar próxima à betoneira, para ser facilmente manejada pelo operador (Lopes \& Nascimento, 2012).

Além da betoneira e do aplicador de cimentante também são necessárias telas para secagem das sementes após a peletização, que deve ser a mais rápida possível, para evitar que a semente absorva a umidade utilizada na dissolução do material cimentante. Para facilitar a secagem, os péletes são colocados em uma camada de aproximadamente $1 \mathrm{~cm}$, sobre uma tela fixada em uma armação, de forma que permita a circulação de ar em ambas as faces da massa de péletes (Lopes \& Nascimento, 2012).

Segundo os mesmos autores a aplicação de agrotóxicos tais como fungicidas e inseticidas deve ser feita na fase intermediária do processo, de forma diluída no material de enchimento. O processo de peletização dura em média 45 minutos por partida, sem considerar o período de secagem e o tempo para preparo de material. O operador tem que ficar muito atento para identificar o momento de alternar a aplicação dos ingredientes, pois não há como estabelecer critérios exatos para isso. $\mathrm{O}$ volume de cimentante e a quantidade de enchimento são alterados durante o 
processo. Cabe, portanto ao operador, desenvolver a habilidade, sensibilidade e acompanhar visualmente a aplicação dos ingredientes, tomando frequentemente uma amostra para verificar a presença de excesso de material não agregado, a presença de péletes vazios (grânulos sem sementes) e de péletes múltiplos (grânulos muito grandes). É necessário também paralisar algumas vezes o processo de peletização para verificar o acúmulo de material nas paredes da betoneira e nas hastes, bem como para tomar amostra do material que rola no fundo da massa.

\subsection{Resultados de estudos de avaliação do processo, materiais e resistência dos péletes}

A aplicação de uma cobertura sólida e seca, durante o processo de peletização de sementes é composta basicamente por um material inerte de granulometria fina (material de enchimento) e um cimentante solúvel em água, visando dar a estas, nova forma e novo tamanho. São poucos os trabalhos que tratam da avaliação dos ingredientes para peletização de sementes. Todos eles se referem ao processamento dos péletes e nenhum trata de estudos de ingredientes sem utilizar o processo de produção de pélete (Silva \& Nakagawa, 1998b).

Autores como Silva \& Nakagawa (1998a) em razão da falta de metodologia para avaliação de materiais para peletização, desenvolveram métodos para avaliação de cimentantes e de outros materiais, por simulação do processamento de péletes. $\mathrm{O}$ mais adequado consistiu na confecção de blocos-sementes compostos da mistura umedecida de areia mais adesivo, moldados em calha com $10 \mathrm{~cm}$ de comprimento e seção interna quadrada com $0,5 \mathrm{~cm}$ de lado, contendo dez sementes por bloco. Os blocos foram secados e posteriormente colocados para germinar, avaliando-se o comportamento das plântulas em relação às oriundas de sementes nuas.

Foram avaliadas neste estudo de Silva \& Nakagawa (1998a) colas à base de acetato de polivinila das marcas: Cascorez, Grudi Extra, Cascorez Extra, Perapret-va, Cascofix e Tudo Cola, sendo a cola Cascorez Extra a que mostrou os melhores resultados, não prejudicando o crescimento das plântulas, apresentando curto tempo de reidratação e menos de um minuto para a quebra da resistência física. A cola de marca Grudi Extra causou toxidez em plântulas de pepino, reduzindo a porcentagem de germinação e causando a formação de raízes tortuosas e com extremidades necrosadas.
Foram avaliados também os produtos: goma arábica, carboximetilcelulose e croscarmelose, sendo que todos apresentaram características indesejáveis como cimentantes para peletização.

Os mesmos autores em outro estudo (Silva \& Nakagawa, 1998b) desenvolveram metodologias para simular o processo de peletização e avaliar os materiais, isoladamente ou em misturas com cimentantes ou outros ingredientes. A metodologia mais apropriada constituiu-se da aplicação da massa umedecida do material em teste, em um molde no formato de calha, com $10 \mathrm{~cm}$ de comprimento e seção interna quadrada de $0,5 \times 0,5 \mathrm{~cm}$, forrado com papel-toalha umedecido. Após o enchimento dos moldes, fez-se a semeadura e os blocos foram removidos para gerbox, contendo substrato de papel de filtro plissado. Foram testados doze materiais e obtiveram-se os melhores resultados com areia e microcelulose isolados, misturados entre si ou com calcário.

Os materiais termofosfato, concinal e croscarmelose de acordo com Silva \& Nakagawa, (1998b) impediram a germinação das sementes, em contrapartida: calcário puro, caulim, serragem de pinho, serragem de eucalipto e esfagno triturado permitiram alguma germinação, mas todas as plântulas eram anormais. O xaxim triturado permitiu boa germinação, mas com elevado número de plântulas anormais, observando-se também, o crescimento de fungos. A bentonita permitiu o crescimento normal das plântulas, mas formou uma massa compacta e muito pegajosa, o que é característica indesejável como material para enchimento.

Em complementação aos estudos anteriores, os mesmos autores em outro trabalho (Silva \& Nakagawa, 1998c) verificaram a resistência dos péletes produzidos, pois estes devem ser suficientemente rígidos para manterem a sua integridade física durante a classificação, transporte, manuseio ou na semeadura mecanizada, sendo então necessário avaliar a sua resistência para que se possa utilizar a menor concentração possível de cimentantes, sem afetar a qualidade final do produto.

Como resultados deste estudo (Silva \& Nakagawa, 1998c) obteve-se que os péletes confeccionados com areia mais bentonita apresentaram os menores índices de resistência, enquanto que aqueles que receberam acabamento com calcário mais cola à base de acetato de polivinila (PVA), apresentaram resistência intermediária e aqueles confeccionados com cola PVA como único cimentante, apresentaram os maiores índices. 


\subsection{Avaliação da qualidade fisiológica e} Armazenamento de sementes peletizadas

Para sementes peletizadas, embora os estudos tenham tido início há bastante tempo, não existe consenso entre os pesquisadores sobre os métodos de avaliação da qualidade fisiológica e, se os testes utilizados para sementes nuas também apresentam sensibilidade para avaliação destas sementes (Franzin et al., 2004).

Em linhas gerais, segundo Giménez-Sampaio \& Sampaio (1994), se repete a situação na qual os testes utilizados para avaliar a capacidade germinativa e vigor das sementes recobertas são os mesmos que se utilizam para as sementes nuas; entretanto, os resultados não podem ser interpretados da mesma maneira. Considerando o fato de que sementes recobertas demoram mais que as nuas para iniciar a sua embebição e desenvolver seus processos germinativos, se deve ressaltar que um atraso na emergência não pode ser considerado como evidência de baixo vigor. Cabe observar que este atraso na emergência das sementes peletizadas, pode variar em função das características físicas (resistência, lisura) do material revestidor (Oliveira et al., 1998; Mendonça et al., 2007).

Para as sementes peletizadas deve-se ter cuidado com o excesso de umidade, pois ele prejudica fortemente a germinação, o material utilizado na peletização retém um filme de água em seus poros, prejudicando a troca gasosa entre a semente e o meio externo (Silva \& Nascimento, 2009).

A mensuração desta qualidade nas sementes peletizadas também está na dependência de um ótimo beneficiamento do lote de sementes para se alcançar um máximo de pureza física e vigor, sendo assim diminui-se a incidência de sementes estéreis (chochas), sementes muito pequenas ou pouco vigorosas, bem como partículas de outras substâncias (impurezas) que serão distribuídas no lugar das sementes (Silva \& Nascimento, 2009). Sendo que é perceptível a facilidade na identificação de sementes estéreis, chochas e outros materiais existentes nas sementes nuas em relação às peletizadas.

Para espécies florestais, pouco se sabe sobre o comportamento dessas sementes quando recobertas e armazenadas (Pozitano, 2011). Entretanto, de acordo com Giménez-Sampaio \& Sampaio (2009), pode-se afirmar que os princípios fundamentais para a correta conservação de sementes recobertas são os mesmos que têm sido amplamente reconhecidos para as sementes nuas. Em geral, estes fatores são exatamente o contrário daqueles que proporcionam as melhores condições de germinação. Exemplificando, deve-se manter ao mínimo a atividade metabólica destas sementes, mediante o armazenamento a baixa temperatura e umidade relativa do ar, com o objetivo de diminuir a velocidade de deterioração e controlar a ação dos microrganismos próprios do local de armazenamento.

Um dos poucos estudos sobre armazenamento é o de Oliveira et al. (2003) que afirmam que as sementes revestidas deterioram-se mais rapidamente do que as não revestidas quando armazenadas em embalagem permeável.

\section{CONCLUSÃO}

Considerando que as sementes florestais, apresentam grande variação de tamanho, forma e peso para as diferentes espécies, o uso da peletização apresenta-se como uma alternativa promissora, como forma de uniformizar tamanhos e formatos, favorecendo o seu uso em projetos de restauração ecológica através da melhoria da plantabilidade (mecânica ou manual) e/ou com espécies para as quais foi desenvolvido um trabalho de melhoramento.

A semente peletizada apresenta ainda outras vantagens, pois permite a incorporação de vários produtos que ajudam no bom desenvolvimento da muda, diminuindo os custos de produção. Estes pontos favoráveis ainda estão presentes no processo de produção do pélete, quando há um ganho relativo à segurança no trabalho, pois proporciona uma redução de poeira e inalação (ex. agrotóxicos) pelos operadores e também quanto a proteção ao meio ambiente, através do menor uso de insumos durante o plantio da semente peletizada.

\section{STATUS DA SUBMISSÃO}

Recebido: 13 nov., 2014

Aceito: 20 jul., 2015

AUTOR(ES) PARA CORRESPONDÊNCIA

\section{Sérgio Roberto Garcia dos Santos}

Seção de Silvicultura, Instituto Florestal, Rua do Horto, 931, CEP 02377-000, São Paulo, SP, Brasil e-mail: sergiorgsantos@yahoo.com.br 


\section{REFERÊNCIAS}

Almeida NO. Implantação de matas ciliares por plantio direto utilizando-se sementes peletizadas [tese]. Lavras: Universidade Federal de Lavras; 2004.

Baudet L, Peres WB. Recobrimento de sementes. Seed News [online], 2004 [citado em 2014 nov. 3]; 8(1): 20-23. Disponível em: http://www.seednews.inf.br/portugues/ seed81/artigocapa81.shtml

Baudet L, Peske F. Aumentando o desempenho das sementes. Seed News [online], 2007 [citado em 2014 nov. 3]; 11(5): 22-26. Disponível em: http://www.seednews.inf. br/portugues/seed115/print_artigo115.html

Costa MA. Peletização de sementes de brócolos em leito de jorro cônico [tese]. Campinas: Universidade Estadual de Campinas; 2003. [citado em 2014 nov. 3]. Disponível em: http://www.bibliotecadigital.unicamp. br/document/?code=vtls000303243

Dias RA. Peletização de sementes de Pinus elliottii Engelm. Silvicultura em São Paulo 1973; 8: 25-32.

Falck GL. Recobrimento de sementes de Pinus elliotti Engelm como alternativa para semeadura direta em campo [dissertação]. Pelotas: Faculdade de Agronomia Eliseu Maciel, Universidade Federal de Pelotas; 2005 [citado em 2014 nov. 3]. Disponível em: http://www2.ufpel.edu.br/ tede/tde_busca/arquivo.php?codArquivo $=26$

Franzin SM, Menezes NL, Garcia DC, Roversi T. Avaliação do vigor de sementes de alface nuas e peletizadas. Revista Brasileira de Sementes 2004; 26(2): 114-118. http://dx.doi. org/10.1590/S0101-31222004000200016.

Gadotti C, Puchala B. Revestimento de sementes. Informativo ABRATES [online] 2010 [citado em 2014 nov. 3]; 20(3): 70-71. Disponível: http://www.abrates.org.br/images/ stories/informativos/v20n3/minicurso03.pdf

Giménez-Sampaio T, Sampaio NV. Recobrimento de sementes. Informativo ABRATES 1994; 4(3): 20-52.

Giménez-Sampaio T, Sampaio NV. Recobrimento de sementes de hortaliças. In: Nascimento WM, editor. Tecnologia de sementes de hortaliças. Brasília: Embrapa Hortaliças; 2009. p. 275-306.

Instituto de Pesquisas e Estudos Florestais - IPEF. Peletização aprimora produção do setor de sementes. IPEF Notícias [online] 2004 [citado em 2014 nov. 3]; (171): 8. Disponível em: http://www.ipef.br/publicacoes/ ipefnoticias/ipefnoticias171.pdf

Kanashiro M, Kageyama PY, Márques FCM. Peletizacão de sementes de Eucalyptus spp. Instituto de Pesquisa de Estudos Florestais - IPEF [online] 1978 [citado em 2014 nov. 3]; 17(2): 67-73. Disponível em: http://www.ipef.br/ publicacoes/scientia/nr17/cap05.pdf

Karam D, Magalhães PC, Padilha L. Efeito da adição de polímeros na viabilidade, no vigor e na longevidade de sementes de milho [online]. Sete Lagoas: Embrapa Milho e Sorgo; 2007 [citado em 2014 nov. 3]. Circular Técnica n. 94. Disponível em: http://www.cnpms.embrapa.br/ publicacoes/publica/2007/circular/Circ_94.pdf

Lopes ACA, Nascimento WM. Peletização de sementes de hortaliças [online]. Brasília: Embrapa; 2012 [citado em 2014 nov. 3]. Documentos n. 137. Disponível em: http://www.cnph.embrapa.br/paginas/serie_documentos/ publicacoes2012/doc_137.pdf

Medeiros EM, Baudet L, Peres WB, Eicholz ED. Modificações na condição física das sementes de cenoura em equipamento de recobrimento. Revista Brasileira de Sementes 2004; 26(2): 70-75. http://dx.doi.org/10.1590/ S0101-31222004000200010.

Mendonça EAF, Carvalho NM, Ramos NP. Revestimento de sementes de milho superdoce (sh2). Revista Brasileira de Sementes 2007; 29(2): 68-79. http://dx.doi.org/10.1590/ S0101-31222007000200010.

Montanhim GC. Uso de biomassa de algas para a peletização de sementes e desenvolvimento de plântulas de Bowdichia virgilioides Kunth [dissertação]. São Carlos: Universidade Federal de São Carlos; 2013 [citado em 2014 nov. 3]. Disponível em: http://www.bdtd.ufscar.br/htdocs/ tedeSimplificado//tde_busca/arquivo.php?codArquivo $=6751$

Nascimento JF. Condicionamento fisiológico e peletização de sementes de Guazuma ulmifolia Lam [dissertação]. Lavras: Universidade Federal de Lavras; 2011.

Nascimento WM, Silva JBC, Santos PEC, Carmona R. Germinação de sementes de cenoura osmoticamente condicionadas e peletizadas com diversos ingredientes. Horticultura Brasileira 2009; 27(1): 12-16. http://dx.doi. org/10.1590/S0102-05362009000100003.

Oliveira AP, Ramos LRM, Martins CC. Influência de substratos e temperaturas sobre a germinação e vigor de sementes peletizadas de cenoura (Daucus carota L.). Agropecuária Técnica [online] 1998 [citado em 2014 nov. 3]; 19(1-2): 60-65. Disponível em: http://www.cca.ufpb. br/revista/pdf/1998_6.PDF

Oliveira JA, Guimarães RM, Rosa SDVF. Sementes: inovações tecnológicas no cenário nacional. Informe Agropecuário [online] 2006 [citado em 2014 nov. 3]; 27(232): 59-69. Disponível em: http://www.epamig.br/ index.php?option $=$ com_docman\&task=cat_view\&gid $=141 \&$ dir $=$ DESC \&order $=$ date \&limit $=10 \&$ limitstart $=10$

Oliveira JA, Pereira CE, Guimarães RM, Vieira AR, Silva JBC. Desempenho de sementes de pimentão revestidas com diferentes materiais. Revista Brasileira de Sementes 2003; 25(2): 36-47. http://dx.doi.org/10.1590/S010131222003000400006 .

Oliveira RG, Vieira G, Almeida NO. Viabilidade da utilização de sementes peletizadas em projetos de restauração ecológica. In: III Reunião Científica da Rede CTPetro Amazonia - Manaus; 2010; Manaus. Manaus: INPA; 2010. p. 1-8. 
Oliveira SL. Germinação e capacidade produtiva de Brachiaria brizantha com sementes peletizadas em diferentes veículos [dissertação]. Jataí: Universidade Federal de Goiás; 2008.

Pompéia SL, Pradella DZA, Diniz KM, Santos RP. Comportamento dos manacás-da-serra (Tibouchina sp) semeados por via aérea em Cubatão. In: Anais do II Congresso Nacional sobre Essências Nativas; 1992; São Paulo. São Paulo: UNIPRESS; 1992. p. 506-512.

Pozitano M. Conservação da viabilidade de sementes de Senna macranthera por meio de recobrimento [tese]. Campinas: Faculdade de Engenharia Química, Universidade Estadual de Campinas; 2011 [citado em 2014 nov. 3]. Disponível em: http://www.bibliotecadigital.unicamp. $\mathrm{br} /$ document $/$ ? code $=000817561$

Pradella DZA, Pompéia SL, Martins SE, Diniz KM, Pradella JGC. Peletização de sementes em gel hidrofílico. Revista Brasileira de Sementes 1989; 11(1-3): 43-52. http://dx.doi. org/10.17801/0101-3122/rbs.v11n1p43-52.

Reichenbach J. Film-coating para agregar qualidade e segurança. Seed News 2004; (1): 24-25.

Roos EE, Moore FD III. Effect of seed coating on performance of lettuce seeds in greenhouse soil tests. Journal of the American Society for Horticultural Science 1975; 100(5): 573-576.

Rosso GA. Recobrimento de sementes silvestres em panela rotatória [dissertação]. São Carlos: Universidade Federal de São Carlos; 2013 [citado em 2014 nov. 3]. Disponível em: http://www.bdtd.ufscar.br/htdocs/tedeSimplificado// tde_arquivos/22/TDE-2013-05-16T162340Z-5245/ Publico/5105.pdf

Sá JPG. Leucena: utiltização na alimentação animal [online]. Londrina: IAPAR, 1997 [citado em 2014 nov.
3]. Circular n. 96. Disponível em: http://www.iapar.br/ arquivos/File/zip_pdf/cr96_leucena.pdf

Silva JBC, Nakagawa J. Metodologia para avaliação de materiais cimentantes para peletização de sementes. Horticultura Brasileira 1998a; 16(1): 31-37. http://dx.doi. org/10.1590/S0102-05361998160205.

Silva JBC, Nakagawa J. Métodos para avaliação de materiais de enchimento utilizados na peletização de sementes. Horticultura Brasileira [online] 1998b [citado em 2014 nov. 3]; 16(1): 44-49. Disponível em: http://www. horticulturabrasileira.com.br/index.php?option=com_co ntent\&view=article\&id $=15 \&$ Itemid $=20$

Silva JBC, Nakagawa J. Metodologia para avaliação da resistência de péletes. Horticultura Brasileira 1998c; 16(2): 118-122. http://dx.doi.org/10.1590/S0102-05361998160205.

Silva JBC, Nascimento WM. Peletização de sementes de hortaliças. In: Nascimento WM, editor. Tecnologia de sementes de hortaliças. Brasília: Embrapa Hortaliças; 2009. p. 309-341

Silveira S. Recobertura como medida para proteção da semente. Seed News 1998; (5): 34-35.

Taylor AG, Eckenrode CJ, Straub RW. Seed coating technologies and treatments for onion: challenges and progress. HortScience [online] 2001 [citado em 2014 nov. 3]; 36(2): 199-205. Disponível em: http://hortsci. ashspublications.org/content/36/2/199.full.pdf

Walker C, Araújo MM, Maciel CG, Marcuzzo SB. Viveiro florestal: evolução tecnológica e legalização. Revista Verde [online] 2011 [citado em 2014 nov. 3]; 6(5): 8-14. Disponível em: http://www.gvaa.com.br/revista/index. php/RVADS/article/viewFile/804/pdf_329 